\title{
Restricted gene flow in Chilean barnacles reflects an oceanographic and biogeographic transition zone
}

\author{
C. Zakas ${ }^{1}$, J. Binford ${ }^{2}$, S. A. Navarrete ${ }^{3}$, J. P. Wares ${ }^{1, *}$ \\ ${ }^{1}$ Department of Genetics, University of Georgia, Athens, Georgia 30602, USA \\ ${ }^{2}$ Yale University School of Medicine, New Haven, Connecticut 06510, USA \\ ${ }^{3}$ Estación Costera de Investigaciones Marinas \& Center for Advanced Studies in Ecology and Biodiversity, \\ Pontificia Universidad Católica de Chile, Santiago, Chile
}

\begin{abstract}
Broad scale patterns of genetic structure in coastal communities are strongly affected by both ecological transitions and larval dispersal. Along the Chilean coast, we examined 2 species of co-distributed barnacles, Jehlius cirratus and Notochthamalus scabrosus, which span an ecological transition associated with a sharp increase in larval recruitment. A distinct break in haplotype frequencies in the mitochondrial cytochrome oxidase I (mtCOI) gene was detected in N. scabrosus, with only marginal genetic structure observed in $J$. cirratus, suggesting significant differences in either selective pressures or dispersal ability between the species. The nuclear gene elongation factor $1 \alpha$ was also analyzed in N. scabrosus, and similarly suggested limited gene flow. The sharp genetic transition is downstream of the described ecological transition, effectively mirroring a genetic cline described in a different barnacle species along the North American Pacific coast.
\end{abstract}

KEY WORDS: Phylogeography · Oceanography · Intertidal · Chile · Barnacle · Upwelling · Recruitment

Resale or republication not permitted without written consent of the publisher

\section{INTRODUCTION}

A combination of historical processes and nearshore oceanographic conditions strongly influences the population structure of coastal species. These forces can either change species abundance over short geographic ranges (Connolly et al. 2001, Byers \& Pringle 2006), which may be manifested as strong gradients in population dynamics that can be decoupled from abundance (Hughes et al. 1999), or cause unsuspected distributions of intraspecific genetic diversity (Hoskin 2000, Waters \& Roy 2004, Pringle \& Wares 2007). For many intertidal invertebrate and fish species, larvae may be capable of traversing hundreds of kilometers during their development. Such species generally exhibit a largely panmictic (genetically homogeneous) structure throughout their geographic range (Palumbi 1994, Thorrold et al. 2002, Kinlan \& Gaines 2003); however, the interactions among oceanographic forces (e.g. upwelling fronts, eddies, tidal currents), larval be- havior and ecology, as well as the effects of paleoclimate, may generate or maintain patterns of genetic structure that deviate from this expectation. These influences can be subtle over short timescales, yet have profound effects on the population over longer timescales (Wares et al. 2001, Wares 2002, Marko 2004).

Separating the effects of these processes on local or regional coastal population dynamics requires comparison of species that share some developmental, distributional, or ecological traits (Marko 2004). Such studies of coastal communities with relatively simple and well-studied oceanography and paleoclimate (e.g. those along the northeastern Pacific coast) have identified the importance of (1) larval behavior and/or adaptation to microhabitat conditions (Wares \& Castañeda 2005), (2) population stability through climate change (Arndt \& Smith 1998, Marko 2004, Hickerson \& Cunningham 2005), and (3) the persistence of clines or diversity gradients in the heritable traits or genetic markers of different intertidal species (Wares et al. 
2001, Sotka et al. 2004). A broad examination of how these components shape coastal diversity in the northeastern Pacific coast requires a comparison of this area with other communities with similar characteristics.

The southeastern Pacific coast (i.e. Chile and Peru) shares many broad characteristics with the northeastern Pacific (Strub et al. 1987, Halpin et al. 2004, Thiel et al. 2007). A dominant equatorward offshore circulation (Humboldt Current) sets the stage for the seasonally variable wind-driven upwelling, which is modulated by coastal topography and represents the main source of variation in oceanographic conditions in nearshore waters (Narváez et al. 2006, Aiken et al. 2007, Thiel et al. 2007, Wieters et al. 2009). The biogeography of coastal taxa is relatively well studied (Brattström \& Johanssen 1983, Camus 2001), and major transitions in faunal distribution and recruitment that are associated with both paleoglacial environments (up to $\sim 42^{\circ} \mathrm{S}$; Hulton et al. 2002) and shifting oceanographic regimes have been described (Navarrete et al. 2008). Particularly along the Chilean coastline, there is a demonstrated shift in oceanographic conditions near $31^{\circ} \mathrm{S}$ that is mostly manifested as changes in wind patterns, upwelling regimes and associated variability in sea surface temperature (Hormazabal et al. 2004, Navarrete et al. 2005, Wieters et al. 2009). These oceanographic changes appear to control the concentration and temporal variability of surface phytoplankton in coastal waters (Thomas 1999, Navarrete et al. 2005), as well as the density and dynamics of several invertebrate species in intertidal communities (Broitman et al. 2001, Navarrete et al. 2005, Wieters et al. 2009). Specifically, Navarrete et al. $(2002,2005)$ demonstrated a significant decline in recruitment and adult intertidal abundance in mussel and barnacle species downstream (equatorward) of this break.

To determine whether the oceanographic and ecological processes of this coastline generate predictable interactions between larval dispersal and the potential for local adaptation, we compared patterns of spatial genetic diversity and apparent gene flow in 2 dominant intertidal barnacle species, Jehlius cirratus (Darwin, 1854) and Notochthamalus scabrosus (Darwin, 1854). We focus on an $800 \mathrm{~km}$ segment of the Chilean coastline where a transition in recruitment strength has been discovered for a number of species (including these barnacles) with drifting planktonic larvae. These confamilial species were chosen because they compete for space and other resources (López \& González 2003), and like other sessile intertidal species, their sole opportunity for dispersal is the larval phase. Differences in their intertidal distribution (N. scabrosus is more abundant in the upper part of the mid-intertidal, while $J$. cirratus is most abundant throughout the high intertidal zone; Stephenson \& Stephenson 1972,
Navarrete \& Castilla 1990) and slight differences in their larval dispersal phase ( 8 to $10 \mathrm{~d}$ additional development time in $N$. scabrosus; Venegas et al. 2000) may influence the connectivity of coastal populations across the recruitment break noted above.

Marko (2004) suggested that what appear to be slight differences in the ecology and microhabitat of a species may predict large differences in the historical response of a species to climate change. Given what we know of dispersal, recruitment, and competition in these 2 barnacles, we might predict greater genetic structure in Jehlius cirratus due to its high intertidal distribution: J. cirratus has a somewhat reduced larval period relative to Notochthamalus scabrosus, is outcompeted by $N$. scabrosus in the lower intertidal, and thus could demonstrate greater structure through postsettlement mortality among populations. However, if successful recruitment is partly governed by postsettlement mortality, we may find genetic patterns that are more closely associated with the transition in recruitment strength since this transition alters interspecific competition patterns. Here, we provide evidence for restricted gene flow in both species and a more significant and interesting pattern in N. scabrosus, and discuss the potential implications for coastal ecology and biodiversity along the South American Pacific (SAP) coast.

\section{MATERIALS AND METHODS}

Collection, amplification and sequencing of DNA. Specimens of Notochthamalus scabrosus and Jehlius cirratus were collected from quadrats in the mid and upper intertidal zones of sites along the Chilean coast (Tables $1 \& 2$ ). Adults were stored in $95 \%$ ethanol prior to DNA isolation. DNA was extracted from the soma by dissection of each individual using a DNA purification kit (Puregene, Gentra Systems) and quantified using a spectrophotometer (Nanodrop). The cirri and penis,

Table 1. Collection locations, years, and diversity indices for Jehlius cirratus mitochondrial cytochrome oxidase I (mtCOI). Horizontal line: separation of sites based on a reported recruitment break

\begin{tabular}{|lcccc|}
\hline Site & Latitude & $\begin{array}{c}\text { Collection } \\
\text { year }\end{array}$ & $\begin{array}{c}\text { No. } \\
\text { of ind. } \\
\text { mtCOI }\end{array}$ & $\begin{array}{c}\text { Haplotype } \\
\text { no. }\end{array}$ \\
\hline Huasco & $28^{\circ} 23^{\prime} 41^{\prime \prime} \mathrm{S}$ & 2004 & 21 & 15 \\
Temblador & $29^{\circ} 30^{\prime} 45^{\prime \prime} \mathrm{S}$ & 2004 & 22 & 11 \\
Punta Talca & $30^{\circ} 58^{\prime} 18^{\prime \prime} \mathrm{S}$ & 2004 & 24 & 14 \\
\hline Los Molles & $32^{\circ} 14^{\prime} 58^{\prime \prime} \mathrm{S}$ & 2004 & 28 & 18 \\
Las Cruces & $33^{\circ} 30^{\prime} 53^{\prime \prime} \mathrm{S}$ & 2004 & 29 & 20 \\
Pichilemu & $34^{\circ} 24^{\prime} 20^{\prime \prime} \mathrm{S}$ & 2004 & 31 & 19 \\
\hline
\end{tabular}


Table 2. Collection locations, years, and diversity indices for Notochthamalus scabrosus mitochondrial cytochrome oxidase I $(\mathrm{mtCOI})$ and nuclear elongation factor $1 \alpha(\mathrm{EF} 1 \alpha)$. Horizontal line: separation of sites based on a reported recruitment break. EF1 $\alpha$ haplotype data includes those that occur in only 1 ind.

\begin{tabular}{|c|c|c|c|c|c|c|}
\hline Site & Latitude & Collection year & $\begin{array}{l}\text { No. of ind. } \\
\text { mtCOI }\end{array}$ & Haplotype no. & $\begin{array}{l}\text { No. of ind. } \\
\text { EF1 } \alpha\end{array}$ & Haplotype no. \\
\hline Huasco & $28^{\circ} 23^{\prime} 41^{\prime \prime} \mathrm{S}$ & 2004 & 22 & 16 & 6 & 4 \\
\hline Arrayan & $29^{\circ} 27^{\prime} 04^{\prime \prime} \mathrm{S}$ & 2006 & 6 & 6 & 16 & 10 \\
\hline Temblador & $29^{\circ} 30^{\prime} 45^{\prime \prime} \mathrm{S}$ & 2004,2006 & 36 & 25 & 22 & 12 \\
\hline La Pampilla & $29^{\circ} 57^{\prime} 00^{\prime \prime} \mathrm{S}$ & 2006 & 8 & 8 & 17 & 10 \\
\hline Guanaqueros & $30^{\circ} 11^{\prime} 58^{\prime \prime} \mathrm{S}$ & 2006 & 7 & 5 & 23 & 13 \\
\hline Punta Talca & $30^{\circ} 58^{\prime} 18^{\prime \prime} \mathrm{S}$ & 2004,2006 & 21 & 17 & 17 & 11 \\
\hline Los Molles & $32^{\circ} 14^{\prime} 58^{\prime \prime} \mathrm{S}$ & 2004 & 25 & 13 & 6 & 6 \\
\hline Las Cruces & $33^{\circ} 30^{\prime} 53^{\prime \prime} \mathrm{S}$ & 2004 & 29 & 12 & 5 & 6 \\
\hline Pichilemu & $34^{\circ} 24^{\prime} 20^{\prime \prime} \mathrm{S}$ & 2004 & 25 & 12 & 6 & 5 \\
\hline
\end{tabular}

which are the most identifiable taxonomic features of a barnacle, were retained as voucher tissues.

Polymerase chain reaction (PCR) amplifications were performed on the mitochondrial cytochrome $c$ oxidase I (mtCOI) locus using primers from Folmer et al. (1994). Both Jehlius cirratus and Notochthamalus scabrosus were analyzed at this locus. After showing genetic differentiation in mtCOI (see 'Results'), a coding portion of the nuclear elongation factor $1 \alpha(\mathrm{EF} 1 \alpha)$ gene region was analyzed on individuals of $N$. scabrosus, using taxon-specific primers (ChtEF-F 5'CAGACGCAG GGGCTTGTC; ChtEF-R 5'GCCACAGGGATTTCATC AAG). PCR and cycle sequencing conditions were based on Wares \& Cunningham (2005), with PCR annealing temperatures of 40 and $50^{\circ} \mathrm{C}$ for each locus, respectively. Reactions were sequenced in both directions to reliably confirm heterozygotes (Hare \& Palumbi 1999).

Analysis of DNA sequences. DNA sequence data were edited in CodonCode Aligner v.2.0.4. Sites with a PHRED score (Ewing \& Green 1998) < 20 were considered ambiguous and coded as such. Data were trimmed to eliminate individuals with $>20 \%$ ambiguous base calls. The haplotypic phase of each EF1 $\alpha$ genotype was determined using a Bayesian analysis implemented by PHASE (Stephens et al. 2001) in DnaSP v. 5.0 .0 (Librado \& Rozas 2009) under default conditions based on Sotka et al. (2004). Singleton haplotypes (those occurring only once in the PHASEconstructed data set) were considered potentially spurious reconstructions (i.e. due to sequencing error or other forms of uncertainty, rather than heterozygosity) and were not analyzed further. Sequence data at both loci were used to generate maximum parsimony trees using an unweighted heuristic search with tree bisection-reconnection branch swapping in PAUP 4.0b10 (Swofford 2002). Bootstrap resampling was performed for 1000 full heuristic replicates of each data set (and 10000 fast stepwise addition replicates), and majority- rule consensus values for the 1000 most parsimonious topologies were calculated. A median-joining haplotype network was calculated using NETwORK 4.5.1 (Fluxus Engineering).

Analyses of molecular variance (AMOVA) and corrected pairwise genetic differences between sites $\left(\mathrm{F}_{\mathrm{ST}}\right)$ and regions $\left(\mathrm{F}_{\mathrm{CT}}\right)$, as well as among sites within regions $\left(\mathrm{F}_{\mathrm{SC}}\right)$ were generated using the software Arlequin 3.01 (Schneider et al. 1997). The best-fit model of molecular evolution for each data set was determined using likelihood ratio comparison of likelihood scores in MODELTEST 3.7 (Posada \& Crandall 1998). A series of all geographic comparisons was arranged based on the relative location to the proposed ecological break (i.e. spatial AMOVA). In each species and locus dataset, all possible, spatially contiguous AMOVA groupings were considered as suggested by Dupanloup et al. (2002), although our a priori spatial reference involved sites around the $32^{\circ} \mathrm{S}$ demographic break. The comparison with the strongest $\mathrm{F}_{\mathrm{CT}}$ value was reported. To assess the fit of all data to equilibrium models of gene flow, a test for genetic isolation by distance was performed for each dataset using a Mantel test implemented in GENALEX (Peakall \& Smouse 2006). Sample sites on the Chilean coast are effectively linear, thus a 1-dimensional model of $\mathrm{F}_{\mathrm{ST}} /\left(1-\mathrm{F}_{\mathrm{ST}}\right)$ versus distance $(\mathrm{km})$ was applied (Rousset 1997). Basic population parameters $(\pi)$ and Tajima's D (Tajima 1989) were calculated for each locus per population to examine the demographic and/or selective history at each locus. The significance of Tajima's D was estimated using a beta distribution in Arlequin.

Additionally, mtCOI data were used to estimate migration rates $(\mathrm{M})$ among all populations using the coalescent analysis program MIGRATE-n (Beerli \& Felsenstein 1999, 2001, Beerli 2006). Four runs of MIGRATE-n were conducted using the entire data set ( 2 runs of 750000 total length and 2 longer runs of 900000 length were conducted using the methodology of Turner et al. (2002); 4 additional runs (same analyti- 
cal setup) were conducted using only sequences that belonged to the A clade (see 'Results'). The mean M toward the north $\left(\mathrm{M}_{\mathrm{N}}\right)$ and that toward the south $\left(\mathrm{M}_{\mathrm{S}}\right)$ were calculated for each population (i.e. no $\mathrm{M}_{\mathrm{N}}$ for Huasco, nor $\mathrm{M}_{\mathrm{S}}$ for Pichilemu, was calculated).

\section{RESULTS}

\section{Jehlius cirratus}

Table 1 shows the number of Jehlius cirratus individuals from 6 sites that were sequenced at mtCOI (Genbank accession numbers GU126073-GU126226). The completed dataset was 583 bp, with 32 parsimony informative sites. No substitutions resulted in amino acid replacement. The best-fit model based on either likelihood ratio test (LRT) or Akaike's information criterion (AIC) is a 3-parameter model $(\operatorname{TrN})$ with gamma-distributed rate variation ( $\alpha=0.13)$.

A parsimony network of mtCOI haplotypes is shown in Fig. 1, with the haplotype frequencies per sampled

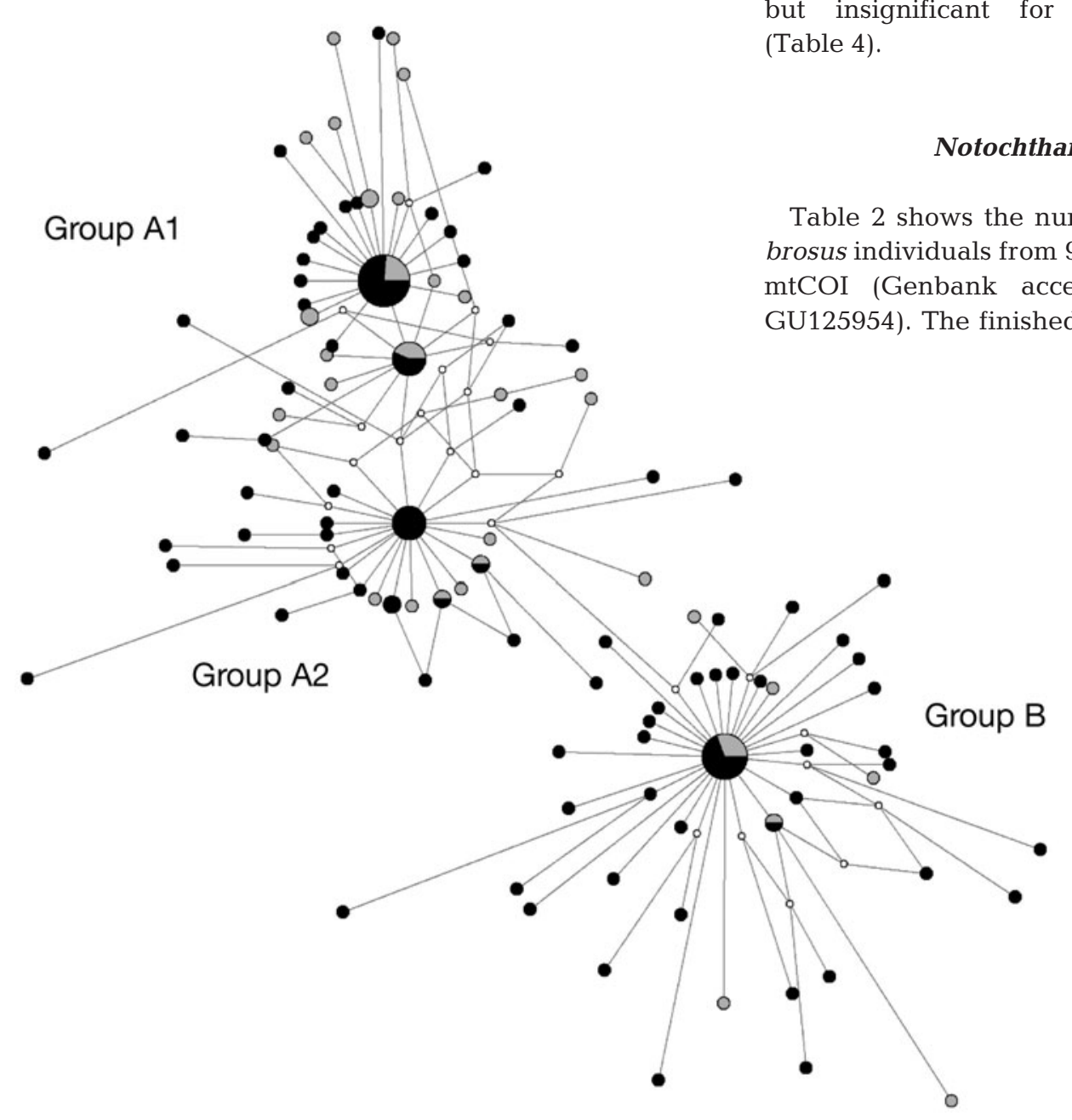

site being indicated. A maximum parsimony tree (of 1000 equally parsimonious trees) for mtCOI shows little statistical (bootstrap) support for clade structure in Jehlius cirratus (not shown). However, strict consensus of these trees supports some clades that differ in relative frequency of geographic representation; 1 monophyletic clade (group A1 in Fig. 1) is 53\% comprised of individuals from the 4 southern populations, while the other monophyletic clade (group B in Fig. 1) is $79 \%$ comprised of individuals from these populations. However, Mantel testing of these data does not show a significant pattern of isolation by distance $\left(R^{2}=0.106\right.$, $\mathrm{p}=0.1)$.

Analysis of molecular variance considering Punta Talca as part of the southern region showed no significant structure (but still the highest $\mathrm{F}_{\mathrm{CT}}$ of all possible contiguous groupings) among regions (Table 3), with $\mathrm{F}_{\mathrm{ST}}=0.032(\mathrm{p}=0.06)$ and $\mathrm{F}_{\mathrm{CT}}=0.027(\mathrm{p}=0.06)$. Similar insignificant results are obtained when Punta Talca is analyzed with the northern populations (not shown) and all other possible groupings. Within-population $\theta$ $(\pi)$ ranged from 5.154 to 8.959 in these 6 populations (Table 4); Tajima's D was negative $(-0.771$ to -1.486$)$ but insignificant for each sampled population (Table 4).

Fig. 1. Jehlius cirratus. Mitochondrial cytochrome oxidase I (MtCOI) gene network. Northern (grey) and southern (black) populations were defined based on the strongest corrected pairwise genetic difference between regions $\left(\mathrm{F}_{\mathrm{CT}}\right)$ in Notochthamalus scabrosus, as in Fig. 2 (i.e. 'southern' is from Punta Talca southward). Note that the relative frequency of individuals from the northernmost populations is higher in phylogroup A1 at the top of the figure (phylogroups do not have strong bootstrap support, but A1 and A2 are defined by $>90 \%$ consensus of maximum parsimony (MP) trees; the B group is recovered with $100 \%$ consensus of MP trees) 
Table 3. Analysis of molecular variance (AMOVA) for Jehlius cirratus comparing sites north and south of $32^{\circ} \mathrm{S}$ and considering Punta Talca as part of the southern region (no site groupings were significant for $\mathrm{F}_{\mathrm{CT}}$ ). Fixation indices (probabilities) are $\mathrm{F}_{\mathrm{SC}}$ : 0.006 $(p=0.06), F_{\text {ST }}: 0.032(p=0.06), F_{C T}: 0.026(p=0.06)$

\begin{tabular}{|llcrrr|}
\hline Locus & Source of variation & df & Sum of squares & Variance components & \% of variation \\
\hline \multirow{2}{*}{ mtCOI } & Among groups & 1 & 9.939 & 0.09627 & 2.66 \\
& Among populations within groups & 4 & 16.058 & 0.01967 & 0.54 \\
& Within populations & 149 & 521.011 & 3.49672 & 96.79 \\
\hline
\end{tabular}

Table 4. Tajima's D statistic and $\theta(\pi)$ for all sites. Significant deviations were estimated in Arlequin using a beta distribution; no Tajima's D tests were significant. CO1: mitochondrial cytochrome oxidase I, EF1 $\alpha$ : nuclear elongation factor $1 \alpha$

\begin{tabular}{|c|c|c|c|c|c|c|c|c|}
\hline \multirow[t]{2}{*}{ Population } & \multicolumn{2}{|c|}{$\begin{array}{c}\text { CO1 in } \\
\text { N. scabrosus }\end{array}$} & \multicolumn{2}{|c|}{$\begin{array}{l}\text { CO1 in } \\
J . \text { cirratus }\end{array}$} & \multicolumn{2}{|c|}{$\begin{array}{c}\text { EF1 } \alpha \text { in } \\
\text { N. scabrosus }\end{array}$} & \multirow[t]{2}{*}{$\begin{array}{c}\text { Observed } \\
\text { heterozygosity }\end{array}$} & \multirow[t]{2}{*}{$\begin{array}{c}\text { Expected } \\
\text { heterozygosity }\end{array}$} \\
\hline & Taj D & $\theta(\pi)$ & Taj D & $\theta(\pi)$ & Taj D & $\theta(\pi)$ & & \\
\hline Huasco & -1.023 & 9.144 & -1.032 & 7.150 & -0.579 & 0.82211 & 0.667 & 0.636 \\
\hline Arrayan & -0.426 & 10.219 & & & -0.719 & 1.31394 & 0.714 & 0.857 \\
\hline Temblador & -1.47 & 9.659 & -1.137 & 5.154 & -1.440 & 1.45395 & 1.000 & 0.530 \\
\hline La Pampilla & -0.977 & 16.525 & & & -0.602 & 1.36061 & 0.733 & 0.752 \\
\hline Guanaqueros & -0.663 & 8.655 & & & -0.659 & 1.39292 & 0.500 & 0.623 \\
\hline Punta Talca & 0.408 & 15.572 & -0.771 & 7.638 & -1.367 & 1.52575 & 1.000 & 0.656 \\
\hline Los Molles & 0.499 & 11.544 & -1.486 & 7.097 & -0.690 & 1.92424 & 1.000 & 0.866 \\
\hline Las Cruces & 1.168 & 14.378 & -1.278 & 7.492 & 0.449 & 1.58678 & 1.000 & 0.733 \\
\hline Pichilemu & 0.789 & 14.344 & -1.372 & 8.959 & -0.818 & 1.56883 & 1.000 & 0.681 \\
\hline
\end{tabular}

parsimony informative sites. No substitutions resulted in amino acid replacement. The best-fit model based on either a LRT or an AIC is a 3-parameter model ( $\operatorname{TrN})$ with invariant/gamma-distributed rate variation $(\alpha=$ 1.1).

A parsimony network of mtCOI haplotypes is shown in Fig. 2, with the haplotype frequencies per sampled site being indicated. A maximum parsimony tree (of 1000 equally parsimonious trees) for mtCOI shows strong statistical support for clade structure in Notochthamalus scabrosus (Fig. 2, bootstrap values shown on network). Two clades with $100 \%$ consensus and $99 \%$ bootstrap support are identifiable; these are called clades A and B (Fig. 2). The A clade can be further separated into 2 subclades, $\mathrm{A}_{1}$ and $\mathrm{A}_{2}$, that are defined by $100 \%$ consensus but low (55\%) bootstrap support. The geographic representation of these clades varies strongly: although all populations were dominated by clade A, clade B was found within $\sim 40 \%$ of southern individuals and almost never found $(<5 \%)$ among northern populations. This geographic shift in haplotype frequency appears to be strongest at $\sim 31^{\circ} \mathrm{S}$ (Fig. 3). There is no significant fit to an isolation by distance model $\left(\mathrm{R}^{2}=0.07, \mathrm{p}=0.09\right)$.

In Notochthamalus scabrosus, AMOVA indicates significant structure among sites and regions (). The strongest $\mathrm{F}_{\mathrm{CT}}$ value is obtained when all populations from Punta Talca southward are grouped together. An overall $\mathrm{F}_{\mathrm{ST}}$ of $0.08(\mathrm{p}<0.01)$ and $\mathrm{F}_{\mathrm{CT}}$ of $0.092(\mathrm{p}=0.01)$ suggest stronger limits to gene flow than in Jehlius cirratus. Similar but insignificant results are obtained when data are analyzed with Punta Talca in the northern group $\left(\mathrm{F}_{\mathrm{CT}}=0.03, \mathrm{p}=0.4\right)$. Additional AMOVA testing with alternative regional structures (e.g. placing the break further north or south) generated no significant regional genetic structure (always a lower $\left.\mathrm{F}_{\mathrm{CT}}\right)$. Within-population $\theta(\pi)$ ranged from 8.655 to 16.525 in these 9 populations (Table 4). Diversity was generally higher in the southernmost populations, and Tajima's D values dramatically shifted from being generally negative and insignificant in northern populations to being positive in the 4 southern populations.

Estimated migration rates (M) from coalescent analysis of sequence data at the mitochondrial mtCOI locus suggest biased dispersal, with the B clade being an important indicator of restricted dispersal. When all sequence data are analyzed without regard to their phylogenetic status, results suggest stronger mean dispersal from north to south (against prevailing currents). Across 4 independent runs of MIGRATE on the entire data set, the ratio of $M_{N}$ to $M_{S}$ ranged from 0.66 to 0.85 . A majority of $\mathrm{M}_{\mathrm{N}}-\mathrm{M}_{\mathrm{S}}$ comparisons for each population indicated higher southward than northward emigration. However, when sequences from the 


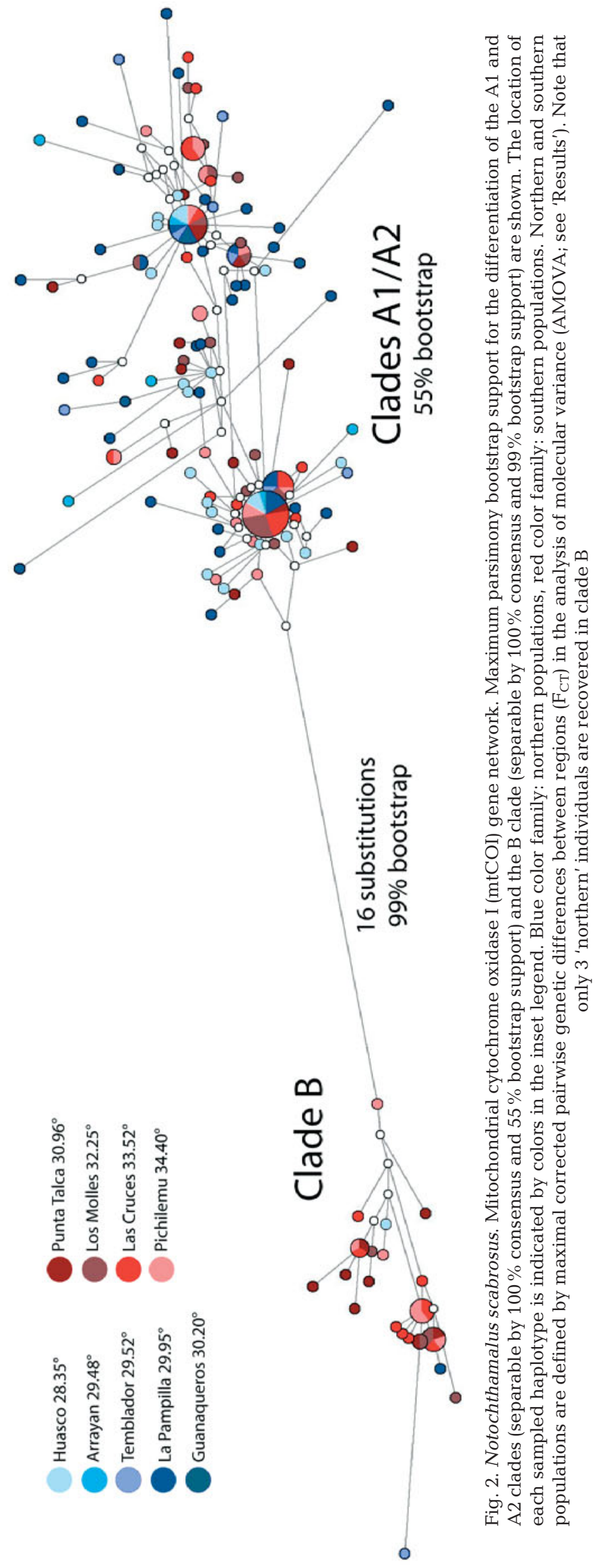

B clade are removed from the data set, the ratio of northward to southward emigration rates shifts to between 1.05 and 1.33 (biased with the prevailing currents). Two (of 72) population comparisons (Los Molles to Pichilemu and Las Cruces to Punta Talca) indicated substantially higher migration than all other values in the pairwise matrix in 2 of the 4 MIGRATE runs and were removed from analysis. Inclusion of these values slightly changed the overall picture but significantly increased the variance across pairwise migration estimates.

These results at the mtCOI locus (deep clade structure, strong geographic shift in haplotype frequency) suggest that further genomic analysis was warranted. Sequence data at EF1 $\alpha$ were collected from individuals as indicated in Tables 1 \& 2 (Genbank accessions GU125955-GU126072). The aligned sequence data were 359 bp in length, with 23 variable sites, 12 of which were parsimony informative. These data BLASTed to a fragment of EF1 $\alpha$ sequence data from Balanus perforatus (E score of 1.31e-145); the entire fragment sequenced for this project is the coding sequence. Only 3 parsimony informative sites resulted in amino acid replacement; 2 of these substitutions were at low frequency $(\leq 2 \%)$, while 1 polymorphism (Val-Met) was found in $32 \%$ of all individuals but with no spatial pattern (see haplotype 4, Fig. 3; it represents $90 \%$ of all individuals carrying this allele). We determined that there were 34 haplotypes of EF1 $\alpha$ in Notochthamalus scabrosus based on PHASE analysis. Of these haplotypes, 5 were common (over $98 \%$ of sampled alleles), while the other 30 were found in only 1 to 3 individuals. A parsimony network of these haplotypes is shown in Fig. 4. No significant structure is obtained through phylogenetic analysis (results not shown). The frequencies of the 5 common haplotypes are shown in Fig. 3 as a representation of the genetic clines from northern to southern populations that are demonstrated in each haplotype class. The Mantel test for isolation by distance at the EF1 $\alpha$ locus in N. scabrosus indicates a significant correlation of pairwise genetic and geographic distances $\left(\mathrm{R}^{2}=0.17, \mathrm{p}=0.04\right)$. MIGRATE analyses of the nuclear EF1 $\alpha$ locus are less informative regarding biased migration, with the overall ratio of inferred northward to southward migration being 0.94 .

Unlike the mtCOI results, AMOVA of EF1 $\alpha$ in Notochthamalus scabrosus indicates insignificant regional structure $\left(\mathrm{F}_{\mathrm{CT}}=-0.01, \mathrm{~ns}\right)$ when Punta Talca is included in the southern region (Table 5). Additional AMOVA testing with all alternative regional structures (e.g. placing the break further north or south along the coast in all possible combinations) generates no significant genetic structure at the regional level. To test for a potential Wahlund effect (a reduction in hetero- 


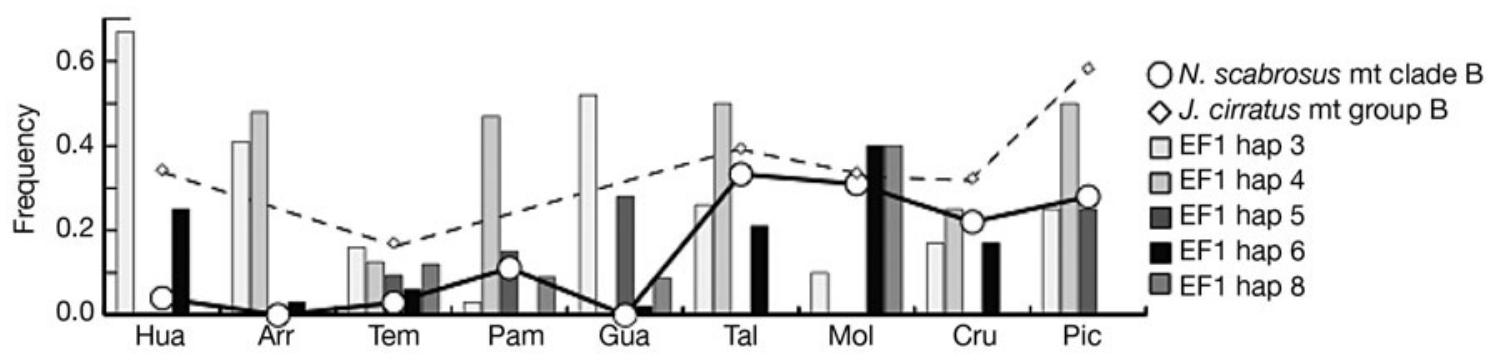

Fig. 3. Haplotype frequencies of the B clade in Notochthamalus scabrosus (O) and of the B phylogroup in Jehlius cirratus ( $\diamond)$ along the Chilean coast from the northernmost (Huasco) to the southernmost site (Pichilemu) (for list of sites see Table 2). The frequency shift of the mitochondrial B clade in N. scabrosus between Guanaqueros $\left(30^{\circ} 11^{\prime} \mathrm{S}\right)$ and Punta Talca $\left(30^{\circ} 58^{\prime} \mathrm{S}\right)$ is significant $(t$-test, $\mathrm{p}<0.001)$. Frequency changes of haplotypes at the nuclear elongation factor $1 \alpha(E F 1 \alpha)$ locus are consistent with isolation by distance; only the 5 most frequent haplotypes are shown

Table 5. Analysis of molecular variance (AMOVA) for Notochthamalus scabrosus mitochondrial cytochrome oxidase I (mtCOI) and nuclear elongation factor $1 \alpha(\mathrm{EF} 1 \alpha)$ comparing localities north and south of the proposed break at $32^{\circ} \mathrm{S}$. All possible groupings were performed but only the grouping that has the largest corrected pairwise genetic difference between regions $\left(\mathrm{F}_{\mathrm{CT}}\right) \mathrm{value}$ (Punta Talca as part of the southern grouping) is shown. For the EF1 $\alpha$ AMOVA, only haplotypes that occurred in $>1$ ind. were used. When Punta Talca is included in the southern region, fixation indices (probabilities) are $F_{\text {IS }}:-0.23393(p=0.99)$, $F_{S C}: 0.17078$ $(p=0.0), F_{C T}:-0.01004(p=0.50), F_{I T}:-0.03347(p=0.80) . F_{I S}$ : corrected pairwise difference for alleles within individuals within subpopulations; $\mathrm{F}_{\mathrm{IT}}$ : corrected pairwise difference for alleles within individuals in the total population

\begin{tabular}{|llcrrrr|}
\hline \multirow{2}{*}{ Locus } & Source of variation & df & Sum of squares & Variance components & \% of variation \\
\hline \multirow{2}{*}{ mtCOI } & Among groups & 1 & 58.263 & 0.61360 & 9.21 \\
& Among populations within groups & 7 & 32.345 & -0.08181 & -1.23 \\
& Within populations & 170 & 1042.338 & 6.13140 & 92.02 \\
EF1 $\alpha$ & 1 & 1.436 & -0.00332 & -1.00 \\
& Among groups & 7 & 11.394 & 0.05706 & 17.25 \\
& Among populations within groups & 22.923 & -0.06481 & -19.59 \\
& Among individuals within populations & 108 & 40.0 & 0.34188 & 103.35 \\
& Within individuals & 117 & & & \\
\hline
\end{tabular}

zygosity due to the inadvertent combination of 2 populations that are not randomly mating), inbreeding coefficients were also measured at the EF1 $\alpha$ locus; in almost all populations, there was a slight excess of heterozygosity (Table 4 ) leading to low and insignificant $F_{\mathrm{IS}}$ and $\mathrm{F}_{\mathrm{IT}}$ values. Tajima's D values at EF1 $\alpha$ were generally negative (Table 4) and insignificant.

\section{DISCUSSION}

The available data for Notochthamalus scabrosus along the SAP coast suggest that, of 2 mitochondrial clades, one (clade B, Fig. 2) has extremely limited success in recruiting to northern populations. In this case, the evidence of limited migration occurs despite a presumed northward movement of larvae due to net SAP coastal currents (Aiken et al. 2007); this contrasts with the relative lack of genetic structure in Jehlius cirratus, suggesting that nearshore currents and their interaction with larval behavior are not the only factors responsible for the genetic cline. This is further supported by the MIGRATE-n results, where the expected oceanographic pattern of downstream (northward) migration is not recovered unless the mtCOI clade B is removed from the analyses. The overall pattern in N. scabrosus is supported by strong regional AMOVA (Table 5), a marginal signal of isolation by distance for the mitochondrial data, as well as a significant $(\mathrm{p}<$ 0.05) pattern of genetic isolation by distance at the nuclear EF1 $\alpha$ locus. The limited gene flow is therefore not necessarily limited by migration, but could reflect significant historical and geographic differentiation of the 2 clades (Fig. 2, Table 5) (Peterson \& Denno 1998, O'Brien \& Freshwater 1999, Wares \& Cunningham 2005, Moyle 2006).

A number of mechanisms may interact to maintain such a phylogeographic pattern. There are effectively 2 mitochondrial lineages with different geographic distributions - one occurring throughout the range of our study, and one limited near the ecological transition caused by shifting coastal upwelling regimes. Tajima's (1989) D statistic allows us to consider intrapopulation diversity for its fit to a model of neutral evolution. While the expectation for this statistic approaches 0 , it is typical for mitochondrial sequence 


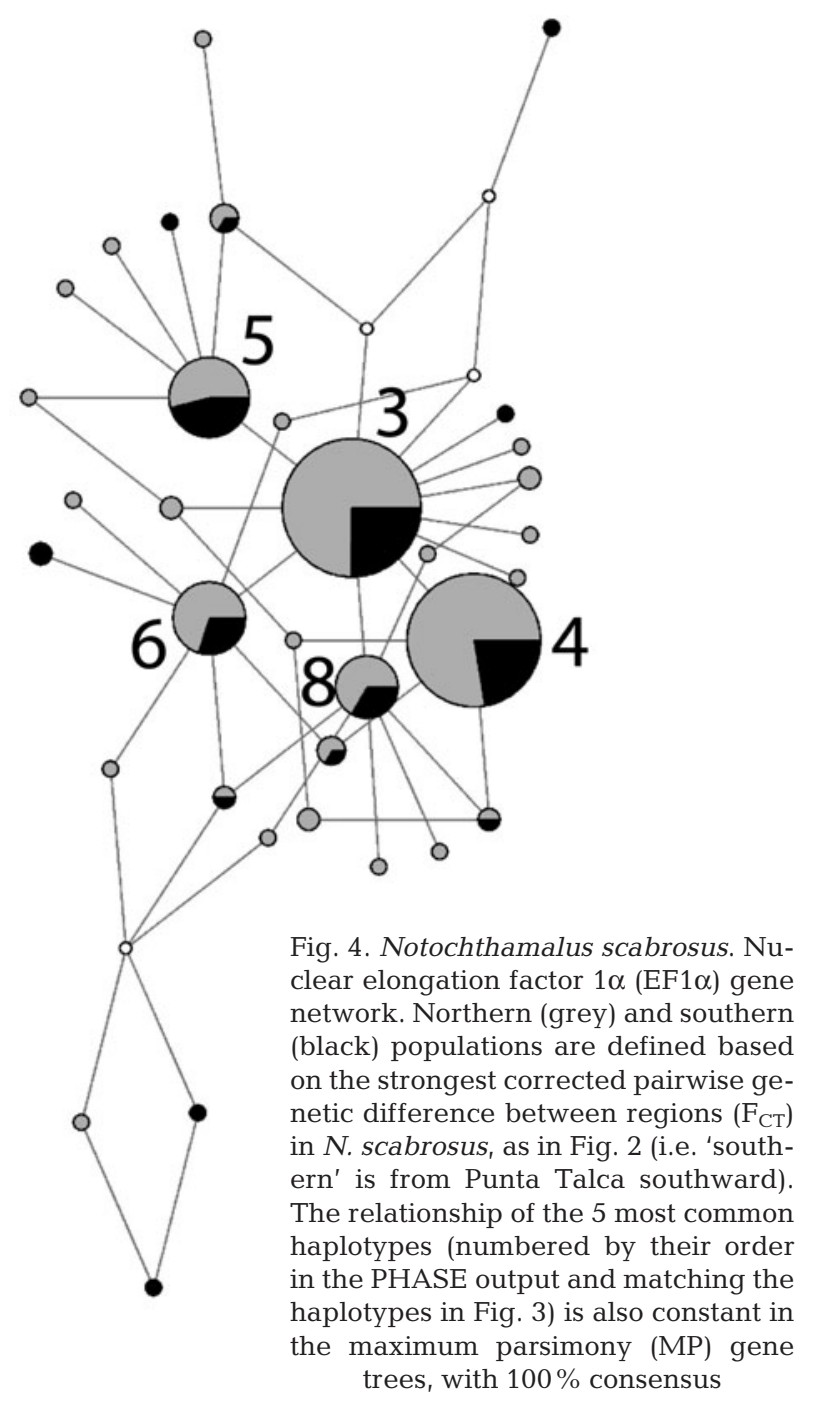

data to be negative due to background selection or demographic effects (e.g. Jehlius cirratus in Table 4; average published D for arthropods $-0.52 \pm 0.97, \mathrm{~J}$. P. Wares in review). This same pattern is observed in northern populations of Notochthamalus scabrosus (Table 4), but southern populations harbor strongly positive D values that could suggest balancing selection, population decline, or other demographic factors. The shift in $\mathrm{D}$ from north to south may indicate a change in the selective pressures acting on these populations. Available data suggest that selection plays a role in maintaining the cline in Balanus glandula on the North American Pacific (NAP) coast (Sotka et al. 2004), but we can only speculate on how selection could also be involved in the diversity patterns of $N$. scabrosus. Unfortunately, no published studies have yet examined patterns of growth, survival or reproduction of $N$. scabrosus across this geographic region that could suggest the existence of varying selection pressures.
A similar pattern of Tajima's D may also indicate the presence of cryptic species. If there is simply a strongly divergent lineage of Notochthamalus scabrosus, we may have only sampled the geographic overlap between the ranges of these lineages. However, in such a case we would expect a Wahlund effect in the nuclear EF1 $\alpha$ genotypic data. Nevertheless, there is no evidence of this effect in our data (Table 4). In fact, inbreeding coefficients illustrate an insignificant excess of heterozygosity (Table 4) with no clear pattern across populations (Table 5), while Tajima's D at this locus is generally slightly negative. Despite the lack of evidence for cryptic speciation in our data, there is the potential for partial reproductive isolation between southern and northern individuals. If partial hybridization is occurring, it would decrease our power to detect a Wahlund effect and only additional markers could fully resolve this possibility. Artifacts of computational haplotype reconstruction could influence these data (although singleton haplotypes were excluded in our presented results, the results are similar when all haplotypes are included), but the overall signal of the nuclear data suggests a single randomly mating species. In both the mtCOI and nEF1 $\alpha$ data, there is a trend toward increased genetic diversity in the southern region (Table 4 ) that may be associated with the higher adult abundance at these sites (Broitman et al. 2001, Navarrete et al. 2005). We attempted to confirm these patterns with additional genetic data (2 nuclear gene regions; C. Zakas unpubl. data) but found insufficient intraspecific diversity in our screening.

The distinction between the A and B clades of Notochthamalus scabrosus is unlikely to be driven by introgression from another similar species; the genetic distance between N. scabrosus and the partially codistributed confamilial Jehlius cirratus is more than an order of magnitude greater $\left(\mathrm{d}_{\mathrm{A}}=0.16\right)$ than the differentiation within N. scabrosus. The significant divergence of these intraspecific clades is unlikely to be due to purely stochastic (coalescent) mechanisms (Hein et al. 2005). It is possible that historic coastal glaciation may have been responsible for the formation of allopatric species that have since come into secondary contact (Dawson 2001). However, the extent of the last glacial maximum (LGM, 19000 to 23000 yr ago) covering the Chilean coast remained at latitudes south of $43^{\circ} \mathrm{S}$ (Hulton et al. 2002), which is outside the range examined in this study, and the net nucleotide divergence between the 2 primary lineages is 0.0180 ; assuming an approximate divergence rate of $3 \%$ per million years (Wares 2001), this divergence could predate the LGM by a few hundred thousand years (Wares \& Cunningham 2005). Whether our study has simply recovered the transition zone between 2 de facto species, or an adaptive cline associated with fit- 
ness of mitochondrial backgrounds requires further evaluation.

In recent years, it has been shown that the Chilean coast is a remarkable global reflection of the same broad processes observed along the California and Oregon coasts (Lagos et al. 2005, Navarrete et al. 2005, Navarrete et al. 2008). Both coasts are subject to strong coastal upwelling and equatorward offshore currents (Strub et al. 1998, Sotka et al. 2004). The similarities between coastal ecological transitions along the Pacific coasts of North and South America, and the associated genetic patterns in barnacle species with planktonic larvae, are intriguing. One case to consider is the 'recruitment break' at Cape Blanco, Oregon $\left(42^{\circ} \mathrm{N}\right.$; Connolly et al. 2001). Nearshore oceanography and latitudinal shifts in the strength of upwelling leads to dramatic shifts in the density of larval recruits across Cape Blanco, with populations to the north experiencing orders of magnitude higher recruitment and higher overall population density. This, in turn, leads to distinct sets of ecological interactions: from a predatordriven 'top down' system described by Paine (1966, 2002) and Menge et al. (1994) to the nutrient-driven system further south (Menge et al. 1997a,b). The nearshore currents surrounding Cape Blanco are likely responsible for the genetic structure recovered across this break in the estuarine crab Hemigrapsus oregonensis (Petersen 2007). For this species, mtCOI haplotypes persisting from the mid-Pleistocene are present in all alongshore populations; however, a more recent and predominant upstream haplotype is absent in populations downstream of Cape Blanco, which is a pattern that Petersen (2007) argued was indicative of historical isolation and population expansion. Our data differ from those of $H$. oregonensis that show a significantly deeper phylogeographic split between the 2 lineages, and suggest that coastal upwelling or selection (or a combination of both) is more likely to determine current haplotype distributions.

Of the barnacle species considered to show a strong recruitment shift around Cape Blanco, the barnacle Balanus glandula exhibits a well-characterized genetic cline (Sotka et al. 2004) that is centered $\sim 400 \mathrm{~km}$ downstream, given the general equatorward flow of coastal currents from the break in intertidal abundance. Other species that exhibit strong recruitment shifts at Cape Blanco (e.g. the barnacle Chthamalus dalli) show no apparent phylogeographic signal at all (Dawson 2001, Wares \& Castañeda 2005). Coastal upwelling and currents drive spatial patterns of density and persistence (Byers \& Pringle 2006) and can generate or maintain effective isolation of otherwise contiguous populations (Rocha-Olivares \& Vetter 1999, Muss et al. 2001, Hare et al. 2005). However, because of complex interactions between coastal advection and the potential for local adaptation (Pringle \& Wares 2007), such genetic transitions (i.e. 'clines'; Endler 1977, Sotka \& Palumbi 2006) may not be found uniformly across species and are not necessarily concordant with inferred ecological transitions.

While the 2 systems (NE Pacific and SE Pacific coasts) are only analogous in pattern, comparative inference of population history and gene flow among species may help identify the deterministic role that physical oceanography may play in the maintenance of coastal biodiversity. The 2 NAP barnacle species with similar adult distribution and general larval biology (Balanus glandula and Cthamalus dalli) provide contrasting evidence of effective larval dispersal: there are apparent limits to gene flow for B. glandula in northern California (Sotka et al. 2004, Wares \& Cunningham 2005), while there is no apparent restriction in gene flow nor any sign of isolation by distance for $C$. dalli (Wares \& Castañeda 2005). Similarly, in this study we show 2 SAP barnacle species respond differentially to the coastal environment. Although these species have a more recent phylogenetic relationship than those in the above studies and much greater biological similarity, they may also differ in larval development time in the field (Venegas et al. 2000), and perhaps in vertical swimming behavior during development. However, there remains a striking signal for restricted gene flow between southern and northern populations of Notochthamalus scabrosus, and only a marginal signal for isolation by distance in the confamilial Jehlius cirratus (a relative uniformity that holds up even when some additional samples from $\sim 600 \mathrm{~km}$ to the south of Pichilemu are included; J. P. Wares unpubl. data).

Marko (2004) suggested that a potential explanation for different phylogeographic patterns in codistributed species with similar larval dispersal mode could be ecological or physiological. Both the high intertidal NAP and high intertidal SAP species under consideration show little to no genetic differences among sites, while the mid-intertidal NAP Balanus glandula and SAP Notochthamalus scabrosus exhibit strong differentiation. However, there are abundant cases of effectively panmictic gene flow in species distributed even lower in the intertidal (e.g. Harley et al. 2006, Ort \& Pogson 2007). The physiological environment along both the NAP and SAP coasts could also drive patterns of local adaptation in species like B. glandula and $N$. scabrosus; while the recognized clines (Fig. 4; Sotka et al. 2004) are not obviously associated with perceived physiological transitions such as those caused by water temperature (Helmuth et al. 2006), air temperature may provide a useful explanation for B. glandula (E. Sotka pers. comm.). Although pelagic larval duration is a good correlate for larval dispersal capabilities and gene flow among distant populations (Kinlan \& Gaines 
2003), many studies have shown that effective dispersal within the same advective environment depends on larval behavior (e.g. diel vertical migration) and position in the water column throughout the dispersal phase (Poulin et al. 2002, Largier 2003, Shanks \& Brink 2005, Guizien et al. 2006). Cyprids of NAP barnacle species tend to stratify in the water column as they do at settlement (Grosberg 1982); however, this stratification remains unexplored in SAP barnacles. Thus, to understand differences in dispersal and population connectivity among species with similar larval duration, it can be critical to have information on larval distribution and behavior in the water column during the dispersal phase.

Regardless of mechanisms, the relative concordance of the genealogical pattern with the recruitment transition around 31 to $32^{\circ} \mathrm{S}$ (Navarrete et al. 2005, Navarrete et al. 2008 ) is worth noting. Although the clines are not exactly coincident with the upwelling-driven ecological transitions, they are downstream of this region by only a generation or so of dispersal by an idealized passive larva (Kinlan \& Gaines 2003, Shanks \& Brink 2005, Pringle \& Wares 2007). The multilocus genetic cline in Balanus glandula (Sotka et al. 2004) is downstream of the Cape Blanco (NAP) recruitment transition by a similar amount, and abiotic forces can certainly displace such patterns from the environmental gradients that cause them (Endler 1977). These signals may be coincident, and we can only speculate as to the interaction between abiotic and biotic mechanisms in maintaining this diversity, but they suggest change in coastal transport associated with change along an adaptive gradient. These mechanisms have been integrated to quantify the strength of selection necessary to maintain intraspecific diversity such as that which we find in B. glandula and Notochthamalus scabrosus (Pringle \& Wares 2007). With further analysis of coastal advection and diffusion, experimental study of selection (e.g. reciprocal transplants), and spatially intensive recruitment plate studies, it may be possible to more closely predict the position of the cline (by relative input from upstream populations) and the selective advantage of downstream populations (Nagylaki 1978, Kawecki \& Holt 2002, Pringle \& Wares 2007), or to better understand these coastal processes in the absence of detectable selection.

Examination of the frequency of B clade individuals in recent larval recruits at northern sites will be of particular interest, as this may indicate whether there is differential mortality among individuals either as larvae or as post-settlement juveniles that is associated with their genetic background. Because B clade individuals are predominantly distributed upstream given prevailing currents (Aiken et al. 2007), we would expect them to have a dispersal advantage in reaching downstream (northern) sites, but they may not be able to survive and recruit. Preliminary recruitment data have been collected (Nov-Jan 2008-09); from a small sample size of 1 to $2 \mathrm{~mm}$ diameter recruits, it appears that the settlement of B clade Notochthamalus scabrosus is similar $\left(\chi^{2}\right.$ test, $\left.\mathrm{p}>0.10\right)$ in populations to the north and south of $31^{\circ} \mathrm{S}$, suggesting that postsettlement mortality may be more important than limits to transport. A gene tree transitional analysis based on Wares et al. (2001) indicates no significant bias in movement of individuals from north to south or viceversa (results not shown); however, coalescent analyses suggest a northward bias in movement of individuals as long as B clade individuals are excluded from analysis (see 'Results').

While the phylogeographic transition in Notochthamalus scabrosus is also concordant with a biogeographic transition between 30 and $32^{\circ} \mathrm{S}$ (Fernandez et al. 2000, Camus 2001), there does not appear to be extensive asymmetry of species with northern and southern boundaries in this region (Brattström \& Johanssen 1983), as might be expected if oceanographic forces were maintaining the transition (Wares et al. 2001). Extension of geographic sampling will be necessary to fully characterize this transition, as both N. scabrosus and Jehlius cirratus are distributed along most of the South American coast from Ecuador to Chile (Brattström \& Johanssen 1983, Venegas et al. 2000). Microhabitat analysis (Power et al. 1999, Wares \& Castañeda 2005) may indicate the roles of environment and gregariousness among species and lineages in maintaining this pattern. Finally, further work on the effect of competition between N. scabrosus and J. cirratus on recruitment success under varying environmental conditions (e.g. López \& González 2003) may be important in understanding both historical and ecological elements (Endler 1982) involved in maintaining this phylogeographic pattern.

The comparison of ecological and evolutionary patterns along the NAP and SAP coasts represents a unique opportunity for replication in phylogeography. Comparative and integrated analysis of ecological transitions (Connolly et al. 2001, Navarrete et al. 2008), changes in behavior associated with these transitions (Sanford et al. 2003), genetic patterns concordant with these transitions (Petersen 2007), and experimental evaluation of fitness (Sanford et al. 2006) at all life stages of coastal invertebrates will ultimately provide significant insights into the function of coastal communities and the diversity they harbor. Currents and their effect on dispersal are clearly responsible for some of these observed patterns, but the environmental changes in climate and topographic conditions, which usually modulate the changes in coastal hydrography, might exert unsuspected and poorly studied selective pressures. We hope these comparisons will allow the 
transformation of such research toward predictions of regions that are most likely to retain larval production and novel diversity (Wares \& Pringle 2008), for application in marine reserve design and coastal fisheries management.

Acknowledgements. We thank S. Pankey and R. Miller for technical assistance on this project, and S. Faugeron and E. Sotka for intellectual contributions that greatly improved the manuscript. Three anonymous reviewers provided helpful comments and ideas that substantially improved the paper. J.P.W. acknowledges funding from the US-Israel Binational Science Foundation (grant \# 2004/239) and the University of Georgia Research Foundation that supported this work. S.A.N. acknowledges FONDECYT grants \# 1070335 and Fondap-Fondecyt 15001-001 for support during sampling of individuals and the continuous support of the Andrew Mellon Foundation during the preparation of this manuscript.

\section{LITERATURE CITED}

Aiken CM, Navarrete SA, Castillo MI, Castilla JC (2007) Alongshore larval dispersal kernels in a numerical ocean model of the central Chilean coast. Mar Ecol Prog Ser 339:13-24

Arndt A, Smith MJ (1998) Genetic diversity and population structure in 2 species of sea cucumbers: differing patterns according to mode of development. Mol Ecol 7:1053-1064

Beerli P (2006) Comparison of Bayesian and maximum likelihood inference of population genetic parameters. Bioinformatics 22:341-345

Beerli P, Felsenstein J (1999) Maximum-likelihood estimation of migration rates and effective population numbers in 2 populations using a coalescent approach. Genetics 152: 763-773

Beerli P, Felsenstein J (2001) Maximum likelihood estimation of a migration matrix and effective population sizes in $n$ subpopulations by using a coalescent approach. Proc Natl Acad Sci USA 98:4563-4568

Brattström H, Johanssen A (1983) Ecological and regional zoogeography of the marine benthic fauna of Chile. Sarsia 68:289-339

Broitman BR, Navarrete SA, Smith F, Gaines SD (2001) Geographic variation in southern Pacific intertidal communities. Mar Ecol Prog Ser 224:21-34

> Byers JE, Pringle JM (2006) Going against the flow: retention, range limits and invasions in advective environments. Mar Ecol Prog Ser 313:27-41

Camus PA (2001) Biogeográfia marina de Chile continental. Rev Chil Hist Nat 74:587-617

Connolly SR, Menge BA, Roughgarden J (2001) A latitudinal gradient in recruitment of intertidal invertebrates in the northeast Pacific Ocean. Ecology 82:1799-1813

> Dawson MN (2001) Phylogeography in coastal marine animals: a solution from California? J Biogeogr 28:723-736

Dupanloup I, Schneider S, Excoffier L (2002) A simulated annealing approach to define the genetic structure of populations. Mol Ecol 11:2571-2581

Endler JA (1977) Geographic variation, speciation, and clines. Princeton University Press, Princeton, NJ, p 262

Endler JA (1982) Problems in distinguishing historical from ecological factors in biogeography. Am Zool 22:441-452

Ewing B, Green P (1998) Base-calling of automated sequencer traces using phred. II. Error probabilities. Genet Res 8: 186-194
Fernandez M, Jaramillo E, Marquet PA, Moreno CA and others (2000) Diversity, dynamics and biogeography of Chilean benthic nearshore ecosystems: an overview and guidelines for conservation. Rev Chil Hist Nat 73:797-830

Folmer O, Black M, Hoeh W, Lutz R, Vrijenhoek R (1994) DNA primers for amplification of mitochondrial cytochrome c oxidase subunit I from diverse metazoan invertebrates. Mol Mar Biol Biotechnol 3:294-299

Grosberg RK (1982) Intertidal zonation of barnacles: the influence of planktonic zonation of larvae on vertical distribution of adults. Ecology 63:894-899

Guizien K, Brochier T, Duchene JC, Koh BS, Marsaleix P (2006) Dispersal of Owenia fusiformis larvae by winddriven currents: turbulence, swimming behaviour and mortality in a 3-dimensional stochastic model. Mar Ecol Prog Ser 311:47-66

Halpin PM, Strub PT, Peterson WT, Baumgartner T (2004) An overview of interactions among oceanography, marine ecosystems, climatic and human disruptions along the eastern margins of the Pacific Ocean. Rev Chil Hist Nat 77 : 371-409

> Hare MP, Palumbi SR (1999) The accuracy of heterozygous base calling from diploid sequence and resolution of haplotypes using allele-specific sequencing. Mol Ecol 8: 1750-1752

Hare MP, Guenther C, Fagan WF (2005) Nonrandom larval dispersal can steepen marine clines. Evolution 59:2509-2517

Harley CDG, Pankey MS, Wares JP, Grosberg RK, Wonham MJ (2006) Color polymorphism and genetic structure in the sea star Pisaster ochraceus. Biol Bull 211:248-262

Hein J, Schierup MH, Wiuf C (2005) Gene genealogies, variation and evolution: a primer in coalescent theory. Oxford University Press, Oxford

Helmuth B, Mieszkowska N, Moore P, Hawkins SJ (2006) Living on the edge of two changing worlds: forecasting the responses of rocky intertidal systems to climate change. Annu Rev Ecol Evol Syst 37:373-404

Hickerson MJ, Cunningham CW (2005) Contrasting quaternary histories in an ecologically divergent sister pair of low-dispersing intertidal fish (Xiphister) revealed by multilocus DNA analysis. Evolution 59:344-360

Hormazabal S, Shaffer G, Leth O (2004) Coastal transition zone off Chile. J Geophys Res 109:C01021

Hoskin MG (2000) Effects of the East Australian Current on the genetic structure of a direct developing muricid snail (Bedeva hanleyi, Angas): variability within and among local populations. Biol J Linn Soc 69:245-262

Hughes TP, Baird AH, Dinsdale EA, Moltschaniwskyj NA, Pratchett MS, Tanner JE, Willis BL (1999) Patterns of recruitment and abundance of corals along the Great Barrier Reef. Nature 397:59-63

> Hulton NRJ, Purves RS, McCulloch RD, Sugden DE, Bentley MJ (2002) The last glacial maximum and deglaciation in southern South America. Quat Sci Rev 21:233-241

Kawecki TJ, Holt RD (2002) Evolutionary consequences of asymmetric dispersal rates. Am Nat 160:333-347

> Kinlan BP, Gaines SD (2003) Propagule dispersal in marine and terrestrial environments: a community perspective. Ecology 84:2007-2020

Lagos NA, Navarrete SA, Véliz F, Masuero A, Castilla JC (2005) Meso-scale spatial variation in settlement and recruitment of intertidal barnacles along the coast of central Chile. Mar Ecol Prog Ser 290:165-178

> Largier JL (2003) Considerations in estimating larval dispersal distances from oceanographic data. Ecol Appl 13: 71-89

Librado P, Rozas J (2009) DnaSP v5: a software for compre- 
hensive analysis of DNA polymorphism data. Bioinformatics 25:1451-1452

López DA, González ML (2003) Density-dependent effects in Jehlius cirratus (Cirripedia: Chthamalidae) under different growth conditions. PSZN I: Mar Ecol 24:289-302

Marko PB (2004) 'What's larvae got to do with it?' Disparate patterns of post-glacial population structure in two benthic marine gastropods with identical dispersal potential. Mol Ecol 13:597-611

Menge BA, Berlow EL, Blanchette CA, Navarrete SA, Yamada SB (1994) The keystone species concept: variation in interaction strength in a rocky intertidal habitat. Ecol Monogr 64:249-286

> Menge BA, Daley BA, Wheeler PA, Dahlhoff E, Sanford E, Strub PT (1997a) Benthic-pelagic links and rocky intertidal communities: bottom-up effects on top-down control. Proc Natl Acad Sci USA 94:14530-14535

Menge BA, Daley BA, Wheeler PA, Strub PT (1997b) Rocky intertidal oceanography: an association between community structure and nearshore phytoplankton concentration. Limnol Oceanogr 42:57-66

Moyle LC (2006) Correlates of genetic differentiation and isolation by distance in 17 congeneric Silene species. Mol Ecol 15:1067-1081

Muss A, Roberston DR, Stepien CA, Wirtz P, Bowen BW (2001) Phylogeography of Ophioblennius: the role of ocean currents and geography in reef fish evolution. Evolution 55:561-572

> Nagylaki T (1978) Clines with asymmetric migration. Genetics 88:813-827

Narváez DA, Navarrete SA, Largier JL, Vargas CA (2006) Onshore advection of warm water, larval invertebrate settlement, and relaxation of upwelling off central Chile. Mar Ecol Prog Ser 309:159-173

Navarrete SA, Castilla JC (1990) Barnacle walls as mediators of intertidal mussel recruitment: effects of patch size on the utilization of space. Mar Ecol Prog Ser 68:113-119

Navarrete SA, Broitman BR, Wieters EA, Finke GR, Venegas RM, Sotomayor A (2002) Recruitment of intertidal invertebrates in the southeast Pacific: inter-annual variability and the 1997-1998 El Niño. Limnol Oceanogr 47:791-802

Navarrete SA, Wieters EA, Broitman BR, Castilla JC (2005) Scales of benthic-pelagic coupling and the intensity of species interactions: from recruitment limitation to topdown control. Proc Natl Acad Sci USA 102:18046-18051

> Navarrete SA, Broitman BR, Menge BA (2008) Interhemispheric comparison of recruitment to rocky intertidal communities: pattern persistence and scales of variation. Ecology 89:1308-1322

O'Brien DL, Freshwater DW (1999) Genetic diversity within tall form Spartina alterniflora Loisel along the Atlantic and Gulf coasts of the United States. Wetlands 19:352-358

> Ort BS, Pogson GH (2007) Molecular population genetics of the male and female mitochondrial DNA molecules of the California sea mussel Mytilus californianus. Genetics 177: 1087-1099

Paine RT (1966) Food web complexity and species diversity. Am Nat 100:65-75

Paine RT (2002) Trophic control of production in a rocky intertidal community. Science 296:736-739

Palumbi SR (1994) Genetic divergence, reproductive isolation, and marine speciation. Annu Rev Ecol Syst 25: 547-572

> Peakall R, Smouse PE (2006) GENALEX 6: genetic analysis in Excel. Population genetic software for teaching and research. Mol Ecol Notes 6:288-295

Petersen CH (2007) Historical demography and contemporary spatial genetic structure of an estuarine crab in the northeast Pacific (Hemigrapsus oregonensis). Mar Biol 150: 1289-1300

Peterson MA, Denno RF (1998) The influence of dispersal and diet breadth on patterns of genetic isolation by distance in phytophagous insects. Am Nat 152:428-446

> Posada D, Crandall KA (1998) MODELTEST: testing the model of DNA substitution. Bioinformatics 14:817-818

Poulin E, Palma AT, Leiva G, Narváez DA, Pacheco R, Navarrete SA, Castilla JC (2002) Avoiding offshore transport of competent larvae during upwelling events: the case of the gastropod Concholepas concholepas in central Chile. Limnol Oceanogr 47:1248-1255

> Power AM, Piyapattanakorn S, O'Riordan RM, Iyengar A and others (1999) Verification of cyprid size as a tool in the identification of two European species of Chthamalus barnacles using mtDNA-RFLP analysis. Mar Ecol Prog Ser 191:251-256

Pringle JM, Wares JP (2007) The maintenance of alongshore variation in allele frequency in a coastal ocean. Mar Ecol Prog Ser 335:69-84

Rocha-Olivares A, Vetter RD (1999) Effects of oceanographic circulation on the gene flow, genetic structure, and phylogeography of the rosethorn rockfish (Sebastes helvomaculatus). Can J Fish Aquat Sci 56:803-813

Rousset F (1997) Genetic differentiation and estimation of gene flow from $F$-statistics under isolation by distance. Genetics 145:1219-1228

Sanford E, Roth MS, Johns GC, Wares JP, Somero GN (2003) Local selection and latitudinal variation in a marine predator-prey interaction. Science 300:1135-1137

Sanford E, Holzman SB, Haney RA, Rand DM, Bertness MD (2006) Larval tolerance, gene flow, and the northern geographic range limit of fiddler crabs. Ecology 87:2882-2894

Schneider S, Kueffer J, Roessli D, Excoffier L (1997) Arlequin ver.1.1: a software for population genetic data analysis.

> Shanks AL, Brink L (2005) Upwelling, downwelling, and cross-shelf transport of bivalve larvae: test of a hypothesis. Mar Ecol Prog Ser 302:1-12

Sotka EE, Palumbi SR (2006) The use of genetic clines to estimate dispersal distances of marine larvae. Ecology 87: 1094-1103

Sotka EE, Wares JP, Barth JA, Grosberg RK, Palumbi SR (2004) Strong genetic clines and geographical variation in gene flow in the rocky intertidal barnacle Balanus glandula. Mol Ecol 13:2143-2156

Stephens M, Smith N, Donnelly P (2001) A new statistical method for haplotype reconstruction from population data. Am J Hum Genet 68:978-989

Stephenson TA, Stephenson A (1972) Life between tidemarks on rocky shores. W.H. Freeman, San Francisco, CA

> Strub PT, Allen JS, Huyer A, Smith RL (1987) Seasonal cycles of currents, temperatures, winds, and sea level over the northeast Pacific continental shelf: $35^{\circ} \mathrm{N}$ to $48^{\circ} \mathrm{N}$. J Geophys Res 92:1507-1526

Strub PT, Mesias JM, Montecino V, Rutllant J, Salinas S (1998) Coastal ocean circulation off western South America, coastal segment $(6, E)$. The Sea 11:273-313

Swofford D (2002) Phylogenetic analysis using parsimony (PAUP) v. 4.0b10. Sinauer Associate, Sunderland, MA

Tajima F (1989) Statistical method for testing the neutral mutation hypothesis by DNA polymorphism. Genetics 123:585-595

Thiel M, Macaya E, Acuna E, Arntz W and others (2007) The Humboldt Current System of northern and central Chile, Vol 45. CRC Press, Boca Raton, FL

Thomas AC (1999) Seasonal distribution of satellite-measured 
phytoplankton pigment concentration along the Chilean coast. J Geophys Res 104:25877-25890

Thorrold SR, Jones GP, Hellberg ME, Burton RS and others (2002) Quantifying larval retention and connectivity in marine populations with artificial and natural markers. Bull Mar Sci 70:s291-s308

> Turner TF, Wares JP, Gold JR (2002) Genetic effective size is three orders of magnitude smaller than adult census size in an abundant, estuarine-dependent marine fish (Sciaenops ocellatus). Genetics 162:1329-1339

> Venegas RM, Ortíz V, Olguín A, Navarrete SA (2000) Larval development of the intertidal barnacles Jehlius cirratus and Notochthamalus scabrosus (Cirripedia: Chthamalidae) under laboratory conditions. J Crustac Biol 20:495-504

Wares JP (2001) Patterns of speciation inferred from mitochondrial DNA in North American Chthamalus (Cirripedia: Balanomorpha: Chthamaloidea). Mol Phylogenet Evol 18:104-116

Wares JP (2002) Community genetics in the Northwestern Atlantic intertidal. Mol Ecol 11:1131-1144

Editorial responsibility: Inna Sokolova,

Charlotte, North Carolina, USA
Wares JP (2009) Natural distributions of mitochondrial sequence diversity support new null hypotheses. Evolution (in press)

Wares JP, Castañeda AE (2005) Geographic range in Chthamalus along the west coast of North America. J Mar Biol Assoc UK 85:327-331

Wares JP, Cunningham CW (2005) Diversification predates glaciation in Balanus glandula. Biol Bull 208:60-68

> Wares JP, Pringle JM (2008) Drift by drift: effective population size is limited by advection. BMC Evol Biol

> Wares JP, Gaines SD, Cunningham CW (2001) A comparative study of asymmetric migration events across a marine biogeographic boundary. Evolution 55:295-306

Waters JM, Roy MS (2004) Phylogeography of a high-dispersal New Zealand seastar: Does upwelling block gene flow? Mol Ecol 13:2797-2806

Wieters EA, Broitman BR, Branch GM (2009) Benthic community structure and spatio-temporal thermal regimes in two upwelling ecosystems: comparisons between South Africa and Chile. Limnol Oceanogr 54:1060-1072

Submitted: February 5, 2009; Accepted: August 10, 2009

Proofs received from author(s): October 23, 2009 